\title{
HISTÓRIA DO PET ENGENHARIA ELÉTRICA UFES
}

Aiury S. Jureswki - aiury.j@gmail.com

Alaf do N. Santos - alaf.ns4@gmail.com

Murilo S. de Mendonça - murilosantolini@gmail.com

Pedro Henrique F. Ulhoa - pedrofabriz2000@ gmail.com

Universidade Federal do Espírito Santo, PET Engenharia Elétrica

Av. Fernando Ferrari, 514 - Goiabeiras 29075-910 - Vitória - ES

Resumo: Este trabalho apresenta um breve apanhado histórico do Programa de Educação Tutorial da Engenharia Elétrica UFES. Nele é contado um pouco das origens do grupo, como é feita a divisão interna de atividades, qual seu impacto na graduação e uma apresentação dos principais projetos realizados ao longo dos anos. É discutido também como o tripé acadêmico se encaixa em meio ao cenário do PET Elétrica e como o grupo se comporta e se organiza diante das normas estabelecidas pelas portarias que regulamentam o programa e o MOB (Manual de Orientações Básicas). O trabalho permite se ter uma visão do PET Elétrica, expondo suas principais características de modo a difundir o que é feito pelo grupo em benefício do curso de Engenharia Elétrica e dos outros grupos PET.

Palavras-chave: PET Engenharia Elétrica. História do PET. PET UFES.

\section{INTRODUÇÃO}

A história do PET Engenharia Elétrica UFES começa em 2006, desde então, foram 4 tutores, um número de projetos difícil de ser mensurado e mais de uma centena de alunos, dentre os quais estão bolsistas e voluntários. Uma característica que já diferencia esse PET é a grande quantidade de projetos efetuada pelo grupo a cada ano, ultrapassando, em média, o número de vinte projetos no total. Como consequência da demanda de tarefas, é comum a presença de voluntários, sendo frequente a equipe total contabilizar o número limite de integrantes (dezoito).

Respeitando a horizontalidade entre todos os membros, sempre houve uma experiência positiva com voluntários, configurando um espaço igual em relação aos bolsistas. Essa característica não esteve somente presente entre os alunos do programa, mas também na sua relação com o tutor. Os tutores, de maneira geral, sempre agiram de forma a guiar e ajudar os tutorandos, pondo de lado a verticalidade, que, muito comumente, inibe o crescimento natural dos alunos por eles orientados. Diante disso, ao longo dos anos, a união do grupo, bem como seu alinhamento com o Manual de Orientações Básicas, fez com que fossem fomentados diversos reflexões e debates que não ficaram internalizados, mas também foram divididas com os outros grupos PET, com a graduação e, até mesmo, o departamento de professores do curso 


\section{ORGANIZAÇÃO DO GRUPO}

Nos últimos anos, o grupo tem se dividido em subgrupos conforme a necessidade de integrantes para um projeto específico. Entretanto, fora as atividades convencionais, no que tange à organização e ao funcionamento do PET em si, o grupo é dividido em quatro equipes administrativas, são elas: Administração, Divulgação, Informática e Recursos Humanos.

A equipe de Recursos Humanos (RH) lida com os processos seletivos, as autoavaliações do grupo e com os relacionamentos internos dos petianos. Nas últimas edições, os processos seletivos têm seguido uma linha de modo a preparar os alunos para os processos dos quais eles farão parte ao longo do curso e da vida. Logo, o processo geralmente é composto de uma prova escrita sobre o programa, um dia de dinâmicas de grupo e apresentações individuais e uma terceira fase com entrevistas realizadas pela equipe de $\mathrm{RH}$, o tutor, outros petianos convidados a compor a comissão avaliadora e um professor convidado do Departamento de Engenharia Elétrica.

O grupo encarregado pela Administração auxilia o tutor na regulamentação dos novos petianos no SIGPET, organiza horários de reuniões, sobretudo, as gerais (administrativas), que ocorrem semanalmente, e são responsáveis pelo inventário e gerência dos materiais físicos do grupo. A equipe de Divulgação é a responsável pela difusão das atividades do PET por meio da produção de textos e imagens a ser compartilhada nas redes sociais dos grupos, além da gerência do site do PET Elétrica junto com a equipe de Informática, responsável pela criação da plataforma Web, manutenção de computadores (software e hardware), além da rede interna da sala do grupo.

\section{INTERAÇÃO DO GRUPO COM A GRADUAÇÃO E COM OUTROS GRUPOS PET}

\subsection{Interação com a graduação}

É de suma importância destacar o papel atuante do PET Elétrica na graduação. Os minicursos aplicados pelo grupo proporcionam uma elevação no nível de capacitação e conhecimento da graduação, embora sejam apenas uma pequena parte de como o grupo contribui para a formação dos alunos.

Logo na chegada do estudante ao curso, é realizada a Semana de Recepção de Calouros, sendo apresentado aos alunos diversos projetos de extensão, regras sobre a universidade, laboratórios e, é claro, o PET. Essa atividade por si só já tem um impacto significativo na graduação, incentivando os alunos a participarem de projetos de pesquisa, monitoria, representação discente e projetos de extensão. Além disso, o contato do grupo com outros programas, projetos e com o departamento durante a execução da atividade proporciona um networking que auxilia o PET Elétrica na promoção de outros projetos.

A política de "portas abertas" assumida pelo PET Elétrica faz com que os estudantes procurem constantemente o grupo para ajuda em disciplinas e projetos. Por esse motivo, é cedido, quando possível, o espaço físico do PET, bem como ferramentas, materiais eletrônicos para os alunos, além do uso de computadores e impressora. Para todos os serviços prestados, existe um livro de registros, no qual, por meio da assinatura, matrícula e motivo do uso do material, é possível documentar as visitas e os empréstimos realizados pelos alunos. Por exemplo, somente no período referente a 2016 até o início de 2019, tivemos em torno de 900 empréstimos contabilizados. Outro diferencial na atuação do grupo em meio à graduação é o auxílio na produção de PCBs (Placas de Circuito Impresso), essenciais em várias disciplinas do curso de Engenharia Elétrica. Além da aplicação de aulas na disciplina de Práticas de 
Laboratório, o PET cede aos alunos o uso de uma plastificadora, álcool, algodão e outros materiais utilizados na fabricação das placas.

\subsection{Interação com outros grupos PET}

Em relação aos outros grupos, sobretudo dos campi da UFES, a qual o grupo pertence, houve diversas integrações ao longo dos anos. O PET Elétrica não só se manteve presente e ativo nas reuniões e eventos do chamado InterPET, como também participa da Comissão Mobiliza UFES desde sua formação em 2017, comissão essa que foi derivada do movimento Mobiliza, iniciado em 2014 e fundado na luta pela permanência e desenvolvimento do programa e de seus integrantes, bem como seus direitos e particularidades. O PET Engenharia Elétrica junto com a comissão Mobiliza UFES engaja-se em um dos objetivos do PET que é contribuir com a política de diversidade na instituição de ensino superior-IES, por meio de ações afirmativas em defesa da equidade socioeconômica, étnico-racial e de gênero. (BRASIL, 2013, p. 24).

Apesar das diversas interações com outros grupos, é necessário ressaltar que alguns projetos foram executados em conjunto com outros PETs, dos quais destaca-se a Jornada de Atualização em Computação, Elétrica e Eletrônica, a JACEE. Esse projeto, instituído em parceria com o PET Engenharia da Computação UFES em 2012, ocorre de forma bienal desde então. O evento é motivo de grande orgulho para o PET Elétrica UFES, não só pelo seu crescimento ao longo dos anos, mas também pelo impacto na formação de vários estudantes, incluindo alunos de cursos que não os de engenharia e mesmo de fora da Universidade Federal do Espírito Santo. Um destaque para o projeto é o fato dele não apenas englobar os três pilares do tripé acadêmico, mas também fazê-lo de maneira conjunta, combinando ensino, pesquisa e extensão.

O evento já teve palestras que contaram não só com professores do curso, mas também com convidados de fora do estado, atuantes em empresas em meio à vanguarda tecnológica atual. Além disso, houve edições com mais de cem horas de minicursos, tanto teóricos quanto práticos, havendo, inclusive, parcerias com outros projetos de extensão. O evento, que dura, em média, quatro dias, tem parcerias com outros projetos de extensão e já foi bem avaliado pelos participantes em diversas ocasiões, obtendo êxito em difundir conhecimento e contemplar os ideais do PET. 


\section{COBENGE de Educação em Engenharia 2020 da ABENGE}

"Os desafios para formar hoje o engenheiro do amanhã"

Figura 1 - JACEE

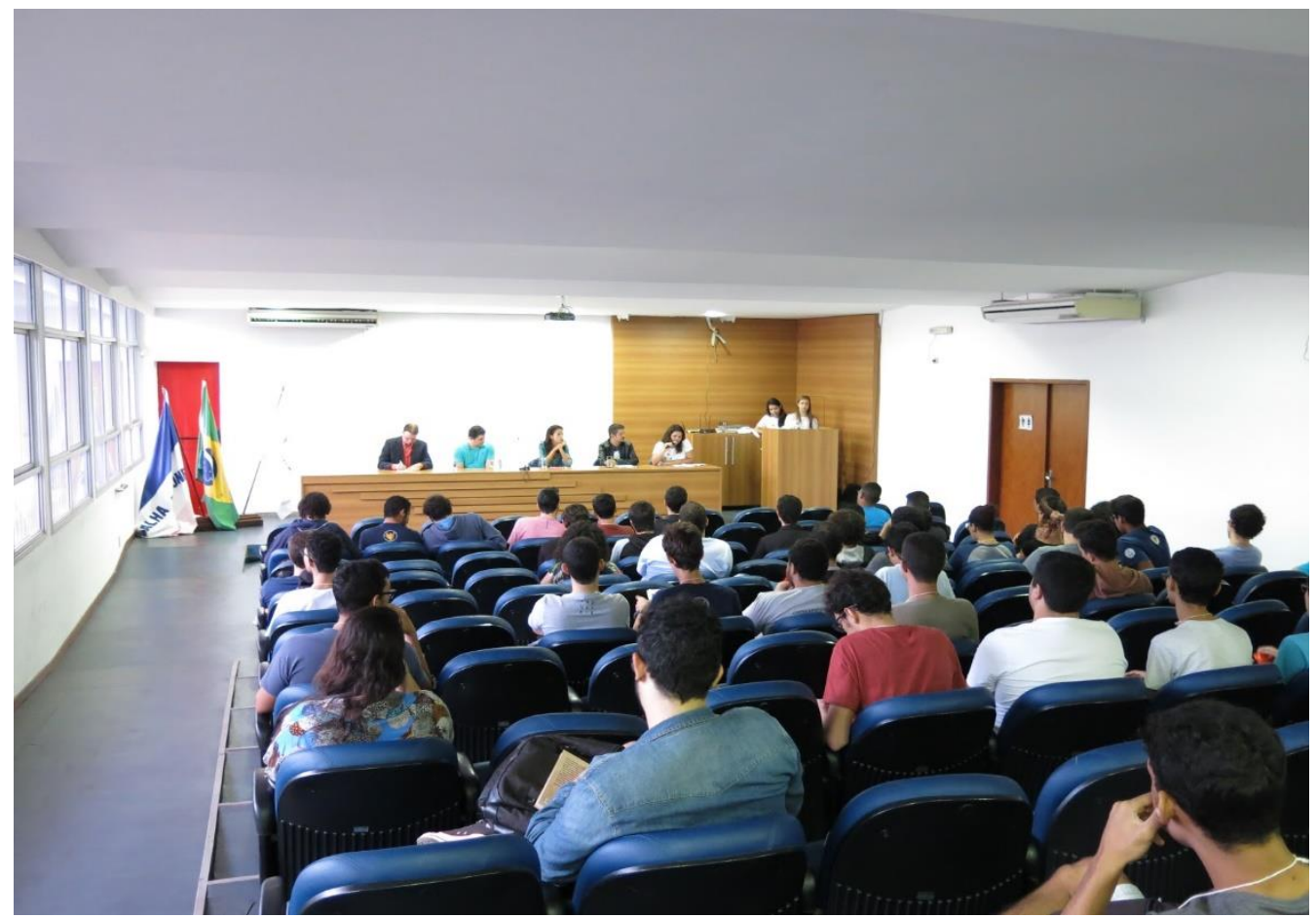

Fonte: Próprios autores.

Outra experiência de interação entre PETs e que merece destaque, é a visita ao Asilo de Vitória, no ano de 2019, junto ao PET Conexões Educação UFES e que teve como objetivo a realização de atividades de recreação com os idosos, como bingo e sorteio de brindes.

Figura 2 - Visita ao Asilo Vitória

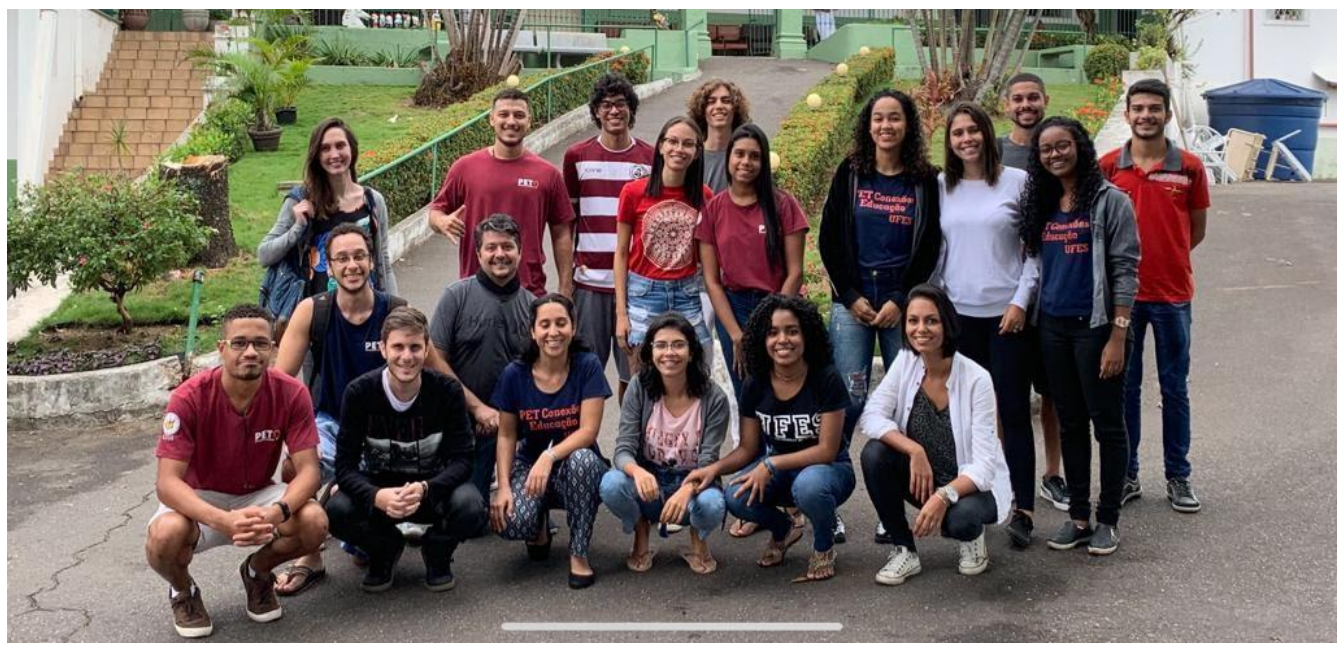

Fonte: Próprios autores.

Muitas dessas ações alinham-se com os objetivos da criação do programa: "Desenvolver atividades acadêmicas em padrões de qualidade de excelência, mediante grupos de aprendizagem tutorial de natureza coletiva e interdisciplinar. Contribuir para a elevação da qualidade da formação acadêmica dos alunos de graduação. Estimular a formação de 
profissionais e docentes de elevada qualificação técnica, científica, tecnológica e acadêmica. Formular novas estratégias de desenvolvimento e modernização do ensino superior no país. Estimular o espírito crítico, bem como a atuação profissional pautada pela ética, pela cidadania e pela função social da educação superior." (BRASIL, 2010, p. 40).

\section{PROJETOS DE DESTAQUE}

\subsection{Minicursos}

Sem sombra de dúvida, um eixo de atuação muito importante e que define bem o perfil do PET Engenharia Elétrica UFES são os minicursos desenvolvidos. Ao longo dos anos, ocorreram minicursos de softwares como Eagle, MATLAB, LATEX e Excel, microcontroladores, controladores e embarcados como PIC, Arduino, Raspberry Pi e CLP (Controladores Lógico Programáveis) e, até mesmo, cursos teóricos como o de Grafos e Redes Complexas. Os minicursos, geralmente abertos não só à graduação do curso de Engenharia Elétrica, são aplicados ao longo do ano, apesar de ocorrem eventualmente nas edições da JACEE e da SENG (Semana da Engenharia).

De todos os projetos realizados pelo grupo, a graduação demonstra um apreço muito grande pelos minicursos ofertados, uma vez que eles os auxiliam em diversas matérias e, ainda, fornecem conteúdo e capacitação para estágios, vagas de emprego e projetos na universidade.

\subsection{PETSocial e SaúdePET}

O grupo também apresenta projetos que agem muito além da engenharia, como o PETSocial. Tendo como base a formação cidadã e a preocupação com o meio social no qual o grupo está inserido e buscando parcerias com o Centro Acadêmico e outros grupos PET, são recolhidas centenas de quilos de alimento não perecível, assim como brinquedos e livros, doados a instituições de apoio a crianças, portadores de HIV e idosos. Além das doações, o PET realiza visitas às instituições, fazendo, inclusive, atividades recreativas.

Outro ponto interessante é o projeto SaúdePET, iniciado com o objetivo de buscar o equilíbrio mental e a união dos petianos em meio ao estresse e à pressão existentes no curso, utilizando atividades ao ar livre e de entretenimento como meio para tal. Dado que saúde é o estado de completo bem-estar físico, mental e social e não somente a ausência de doença (CONSTITUIÇÃO DA ORGANIZAÇÃO MUNDIAL DA SAÚDE, 1946).

\subsection{Itueta}

O Projeto Itueta, teve como principal objetivo analisar as soluções e problemas gerados pelos engenheiros, responsáveis pela construção da Usina Hidrelétrica de Aimorés, na execução de sua profissão. A fim de ampliar a visão dos alunos para além das questões técnicas e econômicas.

A Usina Hidrelétrica de Aimorés localiza-se no Rio Doce, próxima à divisa de Minas Gerais e Espírito Santo. Inaugurada no dia 5 de maio de 2006, tem capacidade de geração de 330 MW. Essa obra afetou diretamente os municípios mineiros de Aimorés, Itueta e Resplendor.

O reservatório da usina inundou uma área de $32,9 \mathrm{~km}^{2}$, dos quais $14,6 \mathrm{~km}^{2}$ pertencem ao município de Itueta, inclusive a sua sede que estava na área alagada. A realocação de mais de 1200 habitantes foi realizada causando grandes alterações nas vidas dessas pessoas. Os impactos sociais que a usina gerou levantam questões quanto ao preço do desenvolvimento tecnológico. 
O projeto Itueta foi caracterizado por um objetivo não somente técnico, mas também social, visto que os PETianos fizeram uma visita à cidade mineira e entrevistaram os moradores da região a fim de verificar a visão dos mesmos em relação aos impactos gerados pela criação da Hidrelétrica na cidade, além de visitarem a própria usina e constatarem a perspectiva daqueles que trabalham na hidrelétrica, em especial os engenheiros envolvidos.

Segundo os alunos envolvidos, faz-se necessária a ampliação da visão de mundo fornecida ao aluno de engenharia, pois a formação do engenheiro no que diz respeito às questões humanas e ambientais infelizmente ainda é muito teórica, partidária e distanciada da realidade prática.

\subsection{EmpreendoPET}

Outro projeto impactante realizado pelo PET Elétrica é o EmpreendoPET, o qual possui o objetivo de atualizar os alunos da Graduação sobre o mundo do Empreendedorismo. Sempre foi observado uma capacidade criativa nos alunos do curso de Engenharia e também uma vontade de colocar em prática ideias inovadoras. As micro e pequenas empresas despertam, seja através de ideias inovadoras ou então novos modelos de negócio, como uma nova dimensão de competitividade global por sua flexibilidade de ação, pelo seu potencial de complementaridade com as grandes empresas e por sua capacidade de geração de empregos (VILLELA, 1994). Sendo assim, o EmpreendoPET organiza eventos que promovam um incentivo a esses alunos, trazendo palestrantes fundadores de Startups, profissionais na área de negócios e também pessoas que se formaram em Engenharia Elétrica e abriram empresas.

\section{CONSIDERAÇÕES FINAIS}

Desde sua formação em 2006, o PET Engenharia Elétrica UFES vem contribuindo com a elevação da qualidade da formação acadêmica dos alunos de graduação, contribuindo não apenas com a elevação da qualificação técnica, científica e acadêmica mas também estimulando o desenvolvimento de habilidade e competências que permitam atuar com criticidade, criatividade, exercendo a cidadania e responsabilidade social e política.

Afinal, com um mercado de trabalho cada vez mais exigente e uma sociedade que demanda engenheiros com uma formação não só técnica, mas também com consciência a respeito das questões humanas e ambientais, é mais que necessário que o engenheiro moderno tenha uma formação menos estreita e mais adaptável ao mundo que constantemente está evoluindo.

O engenheiro é uma peça estratégica para que um país possa não só existir, mas também prosperar. Os grupos PET, assim como o PET Elétrica, auxiliam no desenvolvimento e modernização do ensino, porque só e apenas através dele, que um país pode crescer, afinal: "Se a educação sozinha não transforma a sociedade, sem ela, tampouco, a sociedade muda.“ (FREIRE, 1996).

\section{REFERÊNCIAS}

DIAS, F. J.; NUNES, R. S. Acompanhamento de Egressos de Cursos de Graduação. In: XVII Colóquio Internacional de Gestão Universitária, 2017, Mar del Plata, Argentina. Anais. Mar del Plata, 2017.

VILLELA, A. As micro, pequenas e médias empresas. Textos para Discussão. BNDES. Rio de janeiro, 1994. 
ANDRIOLA, W. B.; MCDONALD, B. C. Avaliação: Fiat Lux em Educação. Fortaleza: Editora da Universidade Federal do Ceará, 2003.

BIBLIOTECA VIRTUAL DE DIREITOS HUMANOS DA UNIVERSIDADE DE SÃO PAULO. Constituição da Organização Mundial da Saúde em 1946. Disponível em: http://www.direitoshumanos.usp.br/index.php/OMS-Organiza\%C3\%A7\%C3\%A3o-Mundialda-Sa\%C3\%BAde/constituicao-da-organizacao-mundial-da-saude-omswho.html. Acesso em: 20. Jan.2020.

BRASIL. Portaria $n^{\circ} .976$ de 27 de julho de 2010. Dispõe sobre o Programa de Educação Tutorial - PET. Diário Oficial [da] República Federativa do Brasil, Poder Executivo, Brasília, DF, 27 jul. 2010. Seção 1, p. 40.

BRASIL. Portaria $\mathrm{n}^{\circ} .343$ de 24 de abril de 2013. Diário Oficial [da] República Federativa do Brasil, Poder Executivo, Brasília, DF, 24 abr. 2013. Seção 1, p. 24.

FERREIRA, A. D.; PIRES, O. H. Egressos da UTP: percepções e relacionamento. 2010. 52 f. Trabalho de Conclusão de Curso (Graduação) - Faculdade de Ciências Sociais Aplicadas, Universidade Tuiuti do Paraná, Curitiba, 2010.

QUEIROZ, T. P.; DE PAULA, C. P. A. Dimensões do relacionamento entre a universidade e seus egressos por meio da informação: o caso da Universidade Federal de Minas Gerais. Em Questão, Belo Horizonte, v. 22, n. 1, p. 37-66, jan./abr. 2016.

FREIRE, Paulo. Pedagogia da autonomia: saberes necessários à prática educativa. São Paulo: Paz e Terra, 1996. Coleção leitura, p. 21, 2005.

AZZINI, Hader AD; RIBEIRO, Moisés RN; PEDROTI, Lorena P. PROJETO ITUETA: UMA PROPOSTA DE INTRODUÇÃO DE ASPECTOS HUMANOS NO ENSINO DE ENGENHARIA. Aceito para publicação no XXXV Congresso Brasileiro de Educação em Engenharia. 2007.

COELHO, M. S. C.; DE OLIVEIRA, N. C. M. Os Egressos no processo de avaliação. Revista e-Curriculum, São Paulo, v. 9, n. 2, p. 1-19, ago. 2012. 


\title{
HISTORY OF THE PET ELECTRICAL ENGINEERING UFES
}

\begin{abstract}
This paper presents a brief summary of the Program of Tutorial Education (PET) of the Electrical Engineering UFES. Within it, it is told a little about the origins of the group, how the internal division of the activities is made, what its impact on the graduation is and a presentation of the main projects realised throughout the years. It is also discussed how the academic tripod fits amidst a scenario of the PET Electrical and how the group behaves and organizes itself before the norms established by the ordinances that regulate the program and the MOB (Manual of Basic Orientations). The paper allows having a vision of the PET Electrical, exposing its main characteristics in order to diffuse what is done by the group in the benefit of the course of Electrical Engineering and the others PET groups.
\end{abstract}

Keywords: PET Electrical Engineering. History of the PET. PET UFES. 